\title{
Research on Education Problems of Left-Behind Children in Rural Areas from the Perspective of Rural Revitalization Strategy*
}

\author{
Yanli Fu \\ Jilin Engineering Normal University \\ Changchun, China 130052
}

\begin{abstract}
The problem of left-behind children in rural areas is an "institutional product" in the economic and social transformation. The education problem of left-behind children in rural areas is a complication of various social problems at the educational level. The implementation of the Rural Revitalization Strategy will help to solve the "left-behind" problem and help the education of left-behind children in rural areas step into a sound track. Based on the macro background of Rural Revitalization Strategy, this paper analyzes the current situation of rural left-behind children's education, integrates social resources as a whole, and forms a rural leftbehind children education care and support system led by the government and coordinated by multiple subjects.
\end{abstract}

Keywords-rural revitalization strategy; rural left-behind children; support system

\section{INTRODUCTION}

Left-behind children refer to a special social group that the rural floating populations leave their minor children in the household registration place when they make a living outside the household registration place; they generally live with one of their father or their mother, or with their grandparents. No.1 document of the Central Committee of the People's Republic of China in 2018, titled "Opinions on the Implementation of Rural Revitalization Strategy", puts forward relevant development measures on rural revitalization, and becomes the key point of "agriculture, rural areas and farmers" in the new era. Unswervingly carrying out the strategy of Rural Revitalization and giving priority to the development of education, especially helping the education development of rural left-behind children, is a major strategic task to win the overall revitalization of rural education and culture. It can not only effectively alleviate the current serious lack of education for rural left-behind children, but also help to realize the balanced and integrated development of urban and rural education.

*Fund: This paper is the phased achievement of the project "Education Problems of Rural Left-behind Children and Countermeasures in Changchun" (No. XYB201724). It is also funded by the school-level scientific research and development fund of Jilin Engineering Normal University.

\section{EDUCATION STATUS OF LEFT-BEHIND CHILDREN IN RURAL AREAS}

As a social phenomenon, the problem of left-behind children in rural areas has existed in ancient times. It is a problem derived from the problem of migrant workers. This problem has attracted great attention from government departments, academic research, policy-making and all sectors of society. With the acceleration of industrialization and urbanization, the education of left-behind children in rural areas has fallen into an increasingly fierce "vortex", and then it is facing an unprecedented crisis and dilemma. The current situation of education of left-behind children in rural areas is mainly reflected in the following aspects.

\section{A. Dotage of Inter-generation Education and Lack of Comprehensive Education}

Under the restriction of dual household registration system in urban and rural areas, migrant workers compare the differences between bringing their children to their side and staying in their hometown from the perspective of economic expenditure, personal safety, and life stability. Most of them choose to entrust their children to grandparents for custody, which is also a reasonable decision made after careful consideration. The education level of grandparents is relatively low, the education mode is backward, and their requirements and standards for children are completely "free feeding"; their traditional education concept often restricts the development of children's creative thinking, and the education content is not innovative and creative; some old people are authoritative and arbitrary, and there is no democracy in the education; China has the traditional concept of "inter-generation love". Grandparents' overindulgence and pampering have created a group of egoistic "little emperors" and "little princesses"; the majority of grandparents are worn with age, unable to carry out outdoor activities with children, limiting the cultivation of children's body, personality and communication ability.

The education of the inter-generation mostly stays on the surface of daily life such as taking care of the left-behind children's daily life. They do not pay enough attention to the comprehensive education of children's morality, intelligence, physique, beauty and labor. In addition, due to old age, poor 


\section{A. Self-closing Psychology}

Most of the left-behind children are born in relatively backward and remote hometown. Their vision is relatively closed, social relations are monotonous, and they have fewer opportunities to contact with others. Many things are unprecedented. Their special family environment makes them care about others' views. Most families are relatively difficult in economy, more afraid of being despised by others, and have strong psychological defense mechanism, which is very easy to lead to self-closing psychology.

\section{B. Poor Sense of Self-identity}

In addition to bearing greater academic pressure, leftbehind children also bear greater family pressure and social pressure compared with urban children, which leads to their improper positioning in self-identity. When compared with urban children involuntarily, they often have a variety of feelings of loss, which will expand the social unfairness onesidedly. Once such negative emotions are expressed in behavior, it is very easy to generate hostile psychology and actions.

\section{Social Interaction Barrier}

Because of the nature of their parents' work and their own conditions, the left-behind children in rural areas seldom get care from their parents. When they communicate with other people, they have problems such as low level of psychological identity, poor awareness of social participation, insufficient social adaptability, and difficult to meet their psychological needs. They are generally faced with different degrees of "social exclusion" in society. In terms of emotional experience, they have experienced certain degree of loneliness and depression.

\section{Distorted Code of Conduct}

Because of inter-generation dotage of left-behind children, weaning of family education and defects of school education, there are some bad factors in the construction of value, such as entertainment, hedonism, instant profit and money worship. The external expression is the bad habits of indolence, extravagance, showing off and so on. They gradually form the extreme character of self-interest and selfreliance, which internally influence and change the value orientation of left-behind children, and distort their cognition of social behavior norms. Even they despise social morality and moral norms.

\section{REFLECTION ON THE EDUCATION PROBLEM OF LEFT- BEHIND CHILDREN IN RURAL AREAS}

not clear, and it is difficult to accurately and effectively support them.

\section{SOCIAL PERFORMANCE OF LEFT-BEHIND CHILDREN IN RURAL AREAS}

In view of the weakening of family education and the defects of school education, the following social manifestations are inevitable for the left-behind children in rural areas.

\section{A. Adverse Impacts of Rapid Growth of Industrialization and Urbanization}

In "Several Opinions of the State Council on Solving the Problem of Migrant Workers", it is pointed out that migrant workers are a new type of labor force emerging in the reform and opening up, industrialization and urbanization in China, and in every industry of urban areas in China. The rapid development of urbanization objectively integrates various 
resource elements in urban and rural areas. Rural labor force continues to be exported to the city, becoming the labor force concentration of urban industrialization. The expected urbanrural integration is not as it is wished. At the same time, the gap between urban and rural development imbalance still exists, and more and more rural left-behind children are an example. Left-behind children are a special group accompanying migrant workers in the industrialization and urbanization.

\section{B. Barrier of the Long-term Dual Household Registration System in Urban and Rural Areas}

As some provinces and cities cancel the restrictions of "agricultural household registration" and "non-agricultural household registration", the reform of household registration system has been put on the agenda, which will undoubtedly benefit the development of left-behind children. However, a series of supporting measures behind the household registration system have not undergone fundamental changes, especially in medical treatment, education, social security and other aspects. Migrant works from rural areas have not been treated fairly. The left-behind children in rural areas are still the special group of "institutional orphans".

Taking the compulsory education funds as an example, the implementation of the compulsory education funds guarantee mechanism is weak. There are obstacles in the implementation of the compulsory education system, and there are large gaps in the rural left-behind children's care and assistance system. In terms of the overall planning of compulsory education in various regions, the allocation of educational resources is still based on the household registration system. Even if migrant workers' children move to the city with their parents, they will not be able to enjoy the same educational resources as urban children, and they also need to pay extra expensive school selection fees and loan fees.

\section{Backward Supporting Facilities of Rural Education}

It is difficult to implement the policy of giving educational hardware facilities and teachers' software facilities in some remote rural areas. In terms of hardware, there is no library, no computer room, and no cultural and entertainment place. In terms of software, because of the development space and salary issues, the mobility of teachers is large. Left-behind children's spare time is very boring, and they can't get their parents' care and teacher's guidance. The conditions cannot be met for them to roam in the ocean of knowledge, and they spend their time in electronic products. The mobile phones left by parents for easy communication and rural Internet cafes have become a paradise for leftbehind children. The operation and management of rural Internet cafes are not standardized. Without the restraint and control of guardians, children are very easy to contact the erosion of bad ideas.

\section{COUNTERMEASURES TO SOLVE THE EDUCATION PROBLEMS OF LEFT-BEHIND CHILDREN IN RURAL AREAS}

Under the macro background of Rural Revitalization Strategy, in order to solve the education problem of rural left-behind children, it is necessary to integrate society, school and family, and build a blue sky for them through collaborative innovation.

\section{A. Protecting the Rights and Interests of Migrant Workers and Strengthening the Function of Family Education}

1) Making migrant workers truly "citizenized": With the gradual strengthening of urban-rural and regional coordinated development in China, the economic strength of the central and western regions is rising rapidly, which makes it possible for home-returning migrant workers to stay in the city. It is certainly not enough to simply and roughly increase the income of migrant workers. While fully considering the income needs of migrant workers, it is necessary to pay attention to whether they have the needs of their children to go to school, whether they have the needs of supporting the elderly, whether they have the needs of buying houses, etc. Relevant government departments should put themselves in a position to think about the needs of migrant workers who are willing to "urbanize", let those who are loaded with luggage and leave their hometown, with the desire to change the poverty situation, use their own hands to change strange cities, and also change the hard situation of migrant workers, to ensure that migrant workers become real citizens and left-behind children do not stay behind. A complete home can be created to these children.

2) Guiding migrant workers to return home for entrepreneurship: Talent revitalization plays an important role in rural revitalization. How to bring talents back and keep them is not only the focus of rural revitalization, but also the difficulty of current rural development. Those migrant workers who are hard to leave their hometown, have strong hometown complex. They have the resources and ability and a strong desire to return to their hometown and start their own businesses. However, facing the difficulties and obstacles of starting their own businesses, the government and relevant departments can work together to crack them, activate this talent group, provide indispensable talent support for the implementation of the Rural Revitalization Strategy, and fundamentally solve the "three left-behind" problems, reducing the lack of family education for left-behind children in rural areas from the root.

\section{B. Playing the Role of the School and Taking the Responsibility of Caring}

1) Increasing investment in education: The education sector should give proper priority to financial and other resources, increase investment in education in left-behind children's areas, and develop and set up boarding schools. The strict management of boarding schools helps the left- 


\section{Caring for Left-behind Children Through Media Publicity}

The media should actively spread the great role of migrant workers in urban development and progress, guide urban residents to enjoy the fruits of urban development, at the same time, objectively recognize the importance of migrant workers, respect and understand the labor of migrant workers, and recognize and encourage migrant workers. The media should pay attention to the positive information transmission of migrant workers, so that left-behind children get the public concern in social life, and vigorously cultivate the public responsibility and social feelings of social organizations.

\section{CONClusion}

Left-behind children are the hope and support of national development. In the macro context of rural revitalization, it is essential to rely on the three main roles of society, school and family tradition, gather forces from all walks of life to cooperate and innovate, pay attention to the physical and mental health and ideological education of rural left-behind children, protect the legitimate rights and interests of leftbehind children, and let them thrive under the warmth and care of the social family. It is also the internal demand to realize the socialist modernization to strengthen the parents' awareness of family parent-child education, guide the school to do a good job in moral education, finally form a harmonious social atmosphere, promote the healthy and orderly development of the left-behind children in rural areas, and better implement the strategic task of rural revitalization.

\section{REFERENCES}

[1] Zhao Feng. Mental Health Status and Educational Strategies of Leftbehind Children in Rural Areas. Journal of Capital Normal University (SOCIAL SCIENCE EDITION), 2010 (03). (in Chinese)

[2] Ding Changqing. Countermeasures for the Implementation of Ideological and Moral Education of Rural Left-behind Children in the Context of Urbanization. Quality Education, 2019 (20). (in Chinese)

[3] Zhang Yue, Zhang Aiqin. Problems and Paths of Family Education of Left-behind Children in the Perspective of "Targeted Poverty Alleviation in Education". Journal of Northwest Institute of Adult Education, 2019 (03). (in Chinese)

[4] Sun Shijin, Social Psychology. Shanghai: Fudan University Press, 2003. (in Chinese)

[5] Chen Liqun, Long Haiying. The Key to Solving the Education Problems of Left-behind Children Lies in "Left-behind Parents. People's Education, 2018 (07). (in Chinese)

[6] Qi Wunian. School Care Model and Discussion of Rural Left-behind Children. Contemporary Education Science, 2017 (02). (in Chinese)

[7] Zhang Xiaoyi, Min Siyu, Yang Qi. Research on the Influence of Care on the Family Environment of Left-behind Children. China Special Education, 2017 (02). (in Chinese)

[8] Luo Huping. Research on the Construction of Education and Social Development Support Network for Rural Left-behind Children under the Strategy of Rural Revitalization. Journal of Xiangnan University, 2018 (06). (in Chinese)

[9] Chen Yuanlong. Inter-generation Education: Social Role Learning Barrier of Rural Left-behind Children. Contemporary Education Forum, 2017 (4). (in Chinese) 